\title{
Primary Schwannoma of the Petrous Apex
}

\author{
Karl L. Horn, M.D., Hal L. Hankinson, M.D., \\ Alan J. Nissen, M.D., \\ and Shawna L. McDaniel, M.S.
}

\begin{abstract}
We present two patients with primary petrous apex schwannoma. These tumors were centered on the petrous carotid artery and are thought to have originated from the deep petrosal nerve. This would account for the paucity of neurologic deficits in these patients. Imaging findings and surgical treatment of primary petrous apex schwannomas are discussed. (Skull Base Surgery, 5(4):261-268, 1995)
\end{abstract}

In the era just prior to the introduction of antibiotics, the petrous apex was an area of great interest to otologist and neurosurgeons. Management of suppurative petrous apicitis and its intracranial complications was the impetus that led to new surgical techniques that we are now finding useful in the treatment of skull base neoplasms. Introduction of antibiotics quieted the arguments about petrous apicitis and little interest was noted in the literature for several decades. Improved imaging techniques and surgical access to the skull base have led to renewed interest in the petrous apex. Although most of this attention in the petrous apex has involved removal of the apex to access the posterior fossa, several reports have reviewed the differential diagnosis and treatment of petrous apex lesions. ${ }^{1-4}$ In the main, lesions of the petrous apex may be divided into lesions arising primarily in the petrous apex and the more frequent lesions that spread from an adjacent or distant area into the petrous apex. Most of the commonly encountered petrous apex lesions arise in temporal bones with pneumatization of the apex and include petrous apicitis, mucocele, cholesterol granuloma, and cholesteatoma. Primary neoplastic lesions of the temporal bone are less frequently encountered and include eosinophilic granuloma, chondrosarcoma, chondroma, chordoma, and schwannoma. Our report presents the clinical findings and treatment of two patients with primary petrous apex schwannoma. The probable neural origin for primary petrous apex schwannoma is also discussed.

CASE REPORTS
Case 1

A 46-year-old woman noted left aural fullness 1 year prior to being seen. This was initially treated with antihistamines and decongestants without benefit. She was seen by her referring physician, who noted a pink mass in the left middle ear. Computed tomography and magnetic resonance imaging were used to evaluate the middle ear mass. Computed tomography using high-resolution bone windows revealed smooth erosion and enlargement of the entire petrous carotid canal (Fig. 1). Enhanced soft tissue windows demonstrated a poorly enhancing mass filling the enlarged carotid canal. Magnetic resonance imaging using $\mathrm{T}_{2}$-weighted imaging showed a poorly enhancing subtemporal mass on the left side (Fig. 2). Gadoliniumenhanced $\mathrm{T}_{1}$-weighted images demonstrated a large enhancing mass filling and enlarging the entire petrous carotid canal (Fig. 3A). The tumor mass was noted to surround most of the circumference of the petrous carotid artery from the carotid foramen to the cavernous sinus (Fig. 3B).

On microscopic examination, the patient was found to have a pink mass filling the anterior mesotympanum. Neurologic testing and audiometric evaluation were nor-

Skull Base Surgery, Volume 5, Number 4, July 1995 Ear Associates, Presbyterian Ear Institute, and Neurosurgical Associates (H.L.H.), Albuquerque, New Mexico Reprint requests: Dr. Horn, Presbyterian Ear Institute, 1114 Cooper Avenue NE, Albuquerque, NM 87106 Copyright (C) 1995 by Thieme Medical Publishers, Inc., 381 Park Avenue South, New York, NY 10016. All rights reserved. 


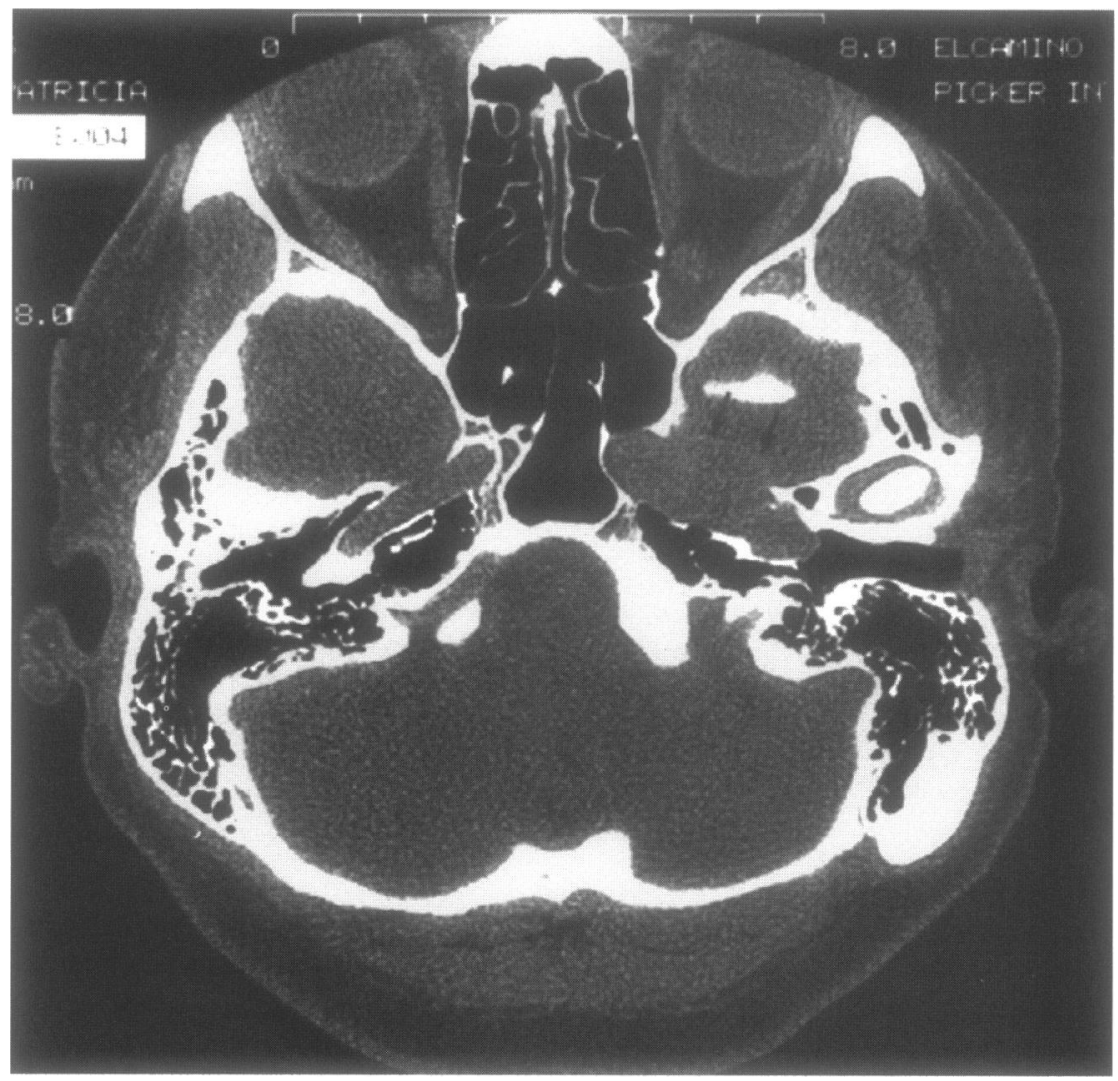

Figure 1. High-resolution computed tomography scan demonstrating neoplastic enlargement of the left carotid canal (arrows).

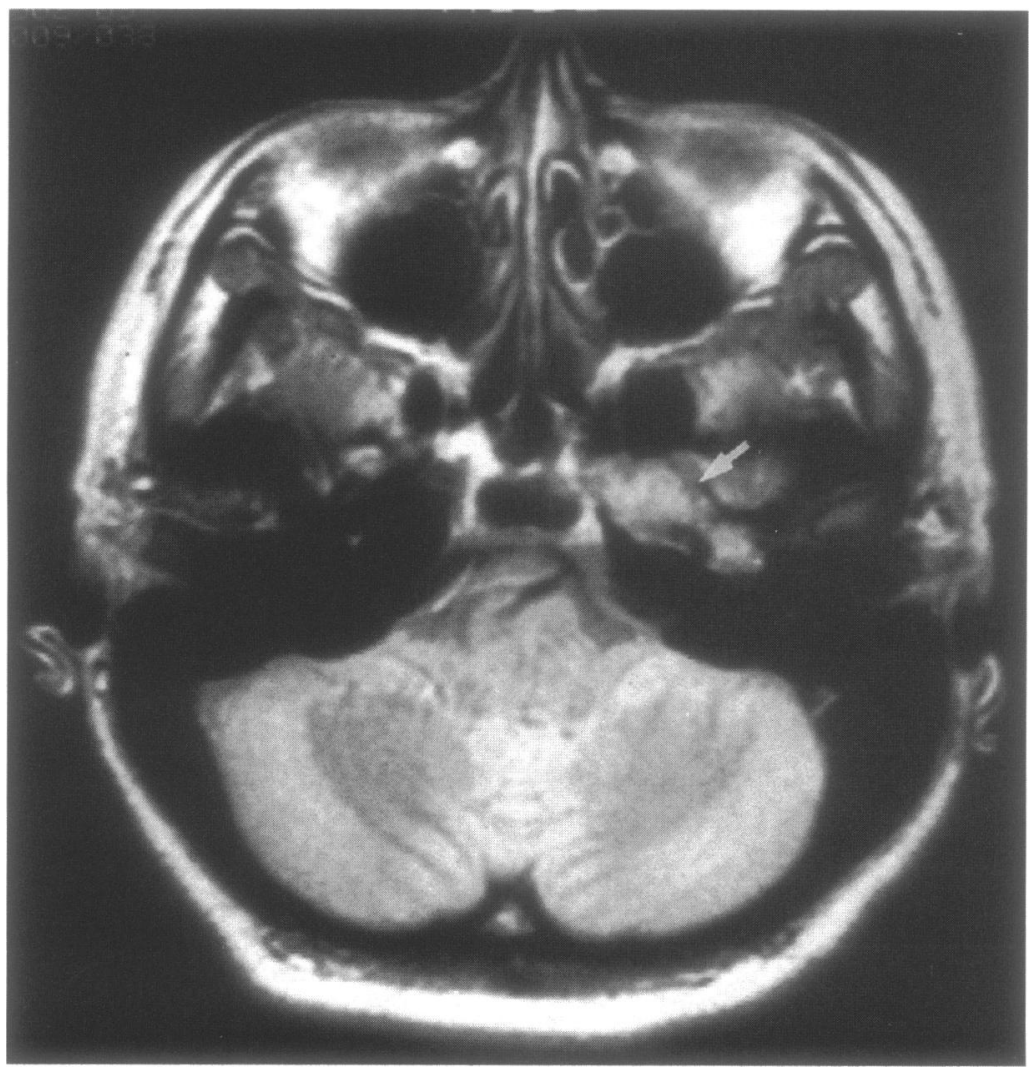

Figure 2. $T_{2}$-weighted magnetic resonance imaging scan showing poorly enhancing mass (arrow) filling and enlarging carotid canal. 
Figure 3. Gadolinium enhanced $\mathrm{T}_{1}$-weighted magnetic resonance imaging scans showing enhancing tumor eroding the horizontal carotid canal and surrounding the petrous carotid artery (arrows).
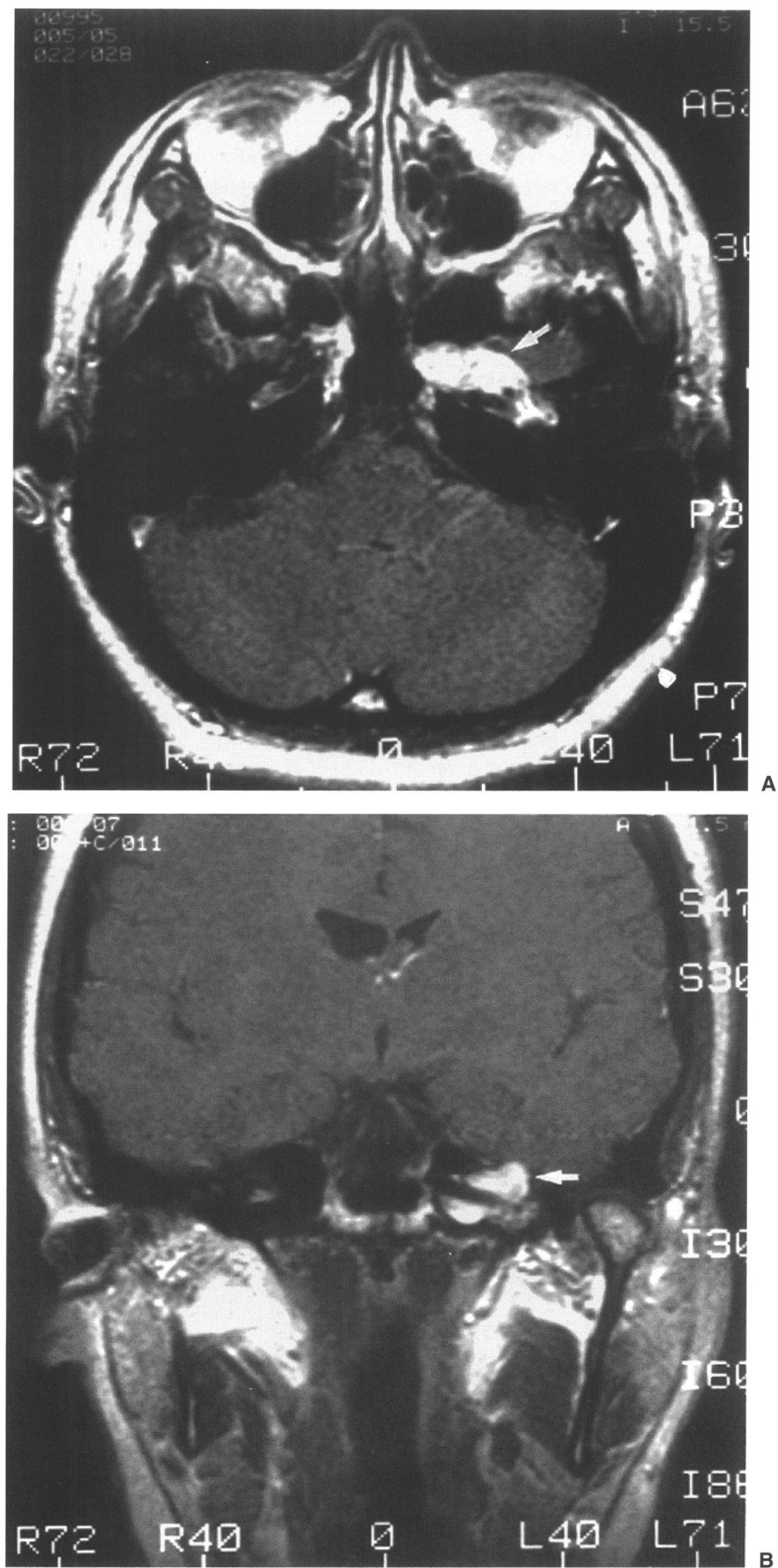
mal. Arteriography showed a normally patent left internal carotid artery. The patient underwent tympanotomy and biopsy of the middle ear mass. Histologic examination demonstrated a spindle cell tumor consistent with a benign schwannoma.

The tumor was excised using a Fisch type B infratemporal fossa approach. A firm fibrous tumor was found to encase the carotid artery from the carotid foramen to the cavernous sinus. Although the tumor was very firm, a dissection plane was present between the tumor mass and the internal carotid artery. The greater petrosal nerve and third division of the trigimenal nerve were both found to be separate from the tumor mass. The greater petrosal nerve was sacrificed for tumor access. All of the tumor was grossly removed. Postoperative imaging revealed a small residual tumor mass in the cavernous sinus (Fig. 4). This mass remains unchanged 3 years postoperatively. The patient continues to have normal cranial nerve function except for loss of tearing due to sacrifice of the greater superficial petrosal nerve and maximal conductive hearing loss secondary to middle ear obliteration.

\section{Case 2}

A 52-year-old man had a several year history of right-sided hearing loss from persistent middle ear effusion. Persistence of the unilateral effusion led to evaluation with computed tomographic imaging. This study demonstrated erosion of the skull base centered on the petrous carotid canal using bone windows and a nonenhancing mass filling the area of erosion in the petrous apex using soft tissue windows (Fig. 5). Magnetic resonance imaging using $T_{2}$-weighted images revealed a right subtemporal mass filling most of the petrous apex and encroaching on the lateral cavernous sinus (Fig. 6). Gadolinium-enhanced $T_{1}$-weighted images revealed an enhancing mass replacing most of the right petrous apex (Fig. 7A). Coronal views showed that the lateral two thirds of the petrous carotid artery was surrounded by the tumor (Fig. 7B). Lateral compression of the petrous carotid artery by the tumor was noted on magnetic resonance arteriography.

Physical examination demonstrated right middle ear effusion and audiometric evaluation showed a mild to moderate right conductive hearing loss. Neurologic testing was normal.

The tumor was removed using a middle fossa transpetrous approach. The tumor was firm and fibrous and nearly completely encased the petrous carotid artery. A good dissection plan between the carotid and the tumor was found except at the posterior carotid genu, where the tumor was densely adherent to the artery. The tumor extended to but not into the cavernous sinus. Complete tumor removal was accomplished except for a small area that was firmly adherent to the posterior genu of the petrous carotid artery. This tumor was coagulated with bipolar cautery. The tumor did not arise from any identi-

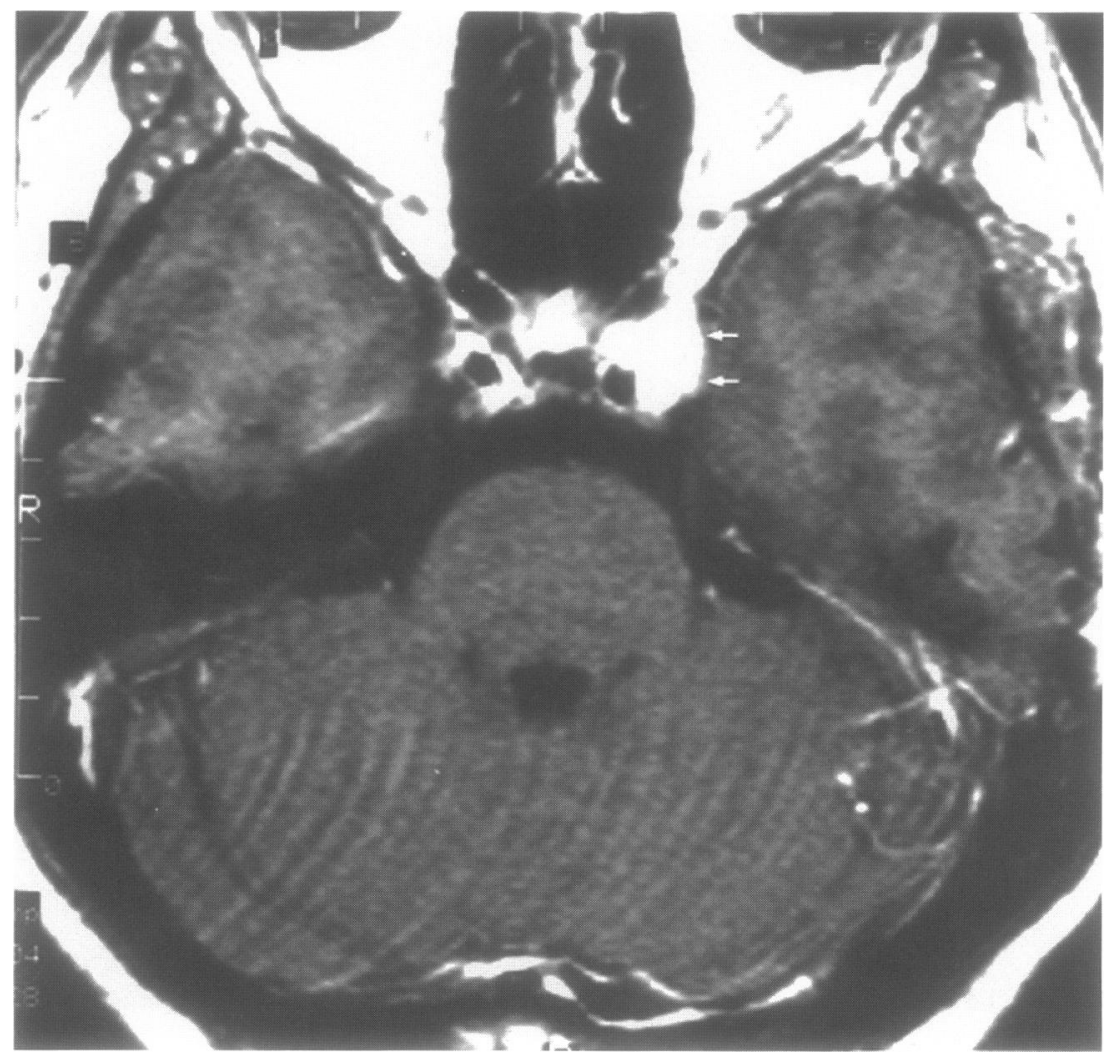

Figure 4. Postoperative gadolinium enhanced $T_{1}$-weighted magnetic resonance imaging scan demonstrating residual tumor in the cavernous sinus (arrows). 
Figure 5. High-resolution computed tomography scan illustrating gross enlargement of the right petrous carotid canal. The small arrow points to the eroded foramen spinosum and the large arrow points to the eroded foramen ovale.

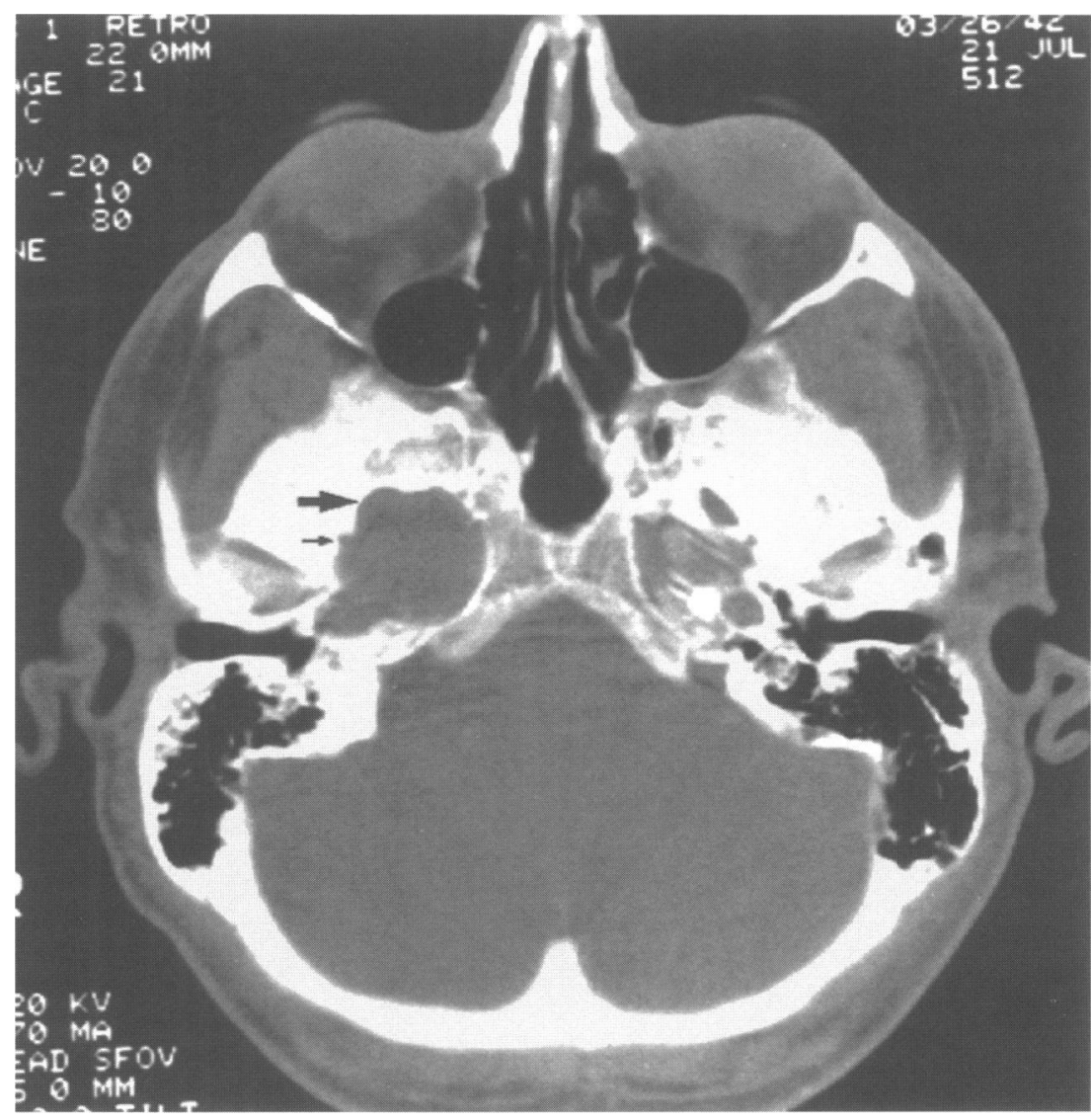

Figure 6. $T_{2}$-weighted magnetic resonance imaging scan showing poorly enhancing tumor (arrow) in the right carotid canal.

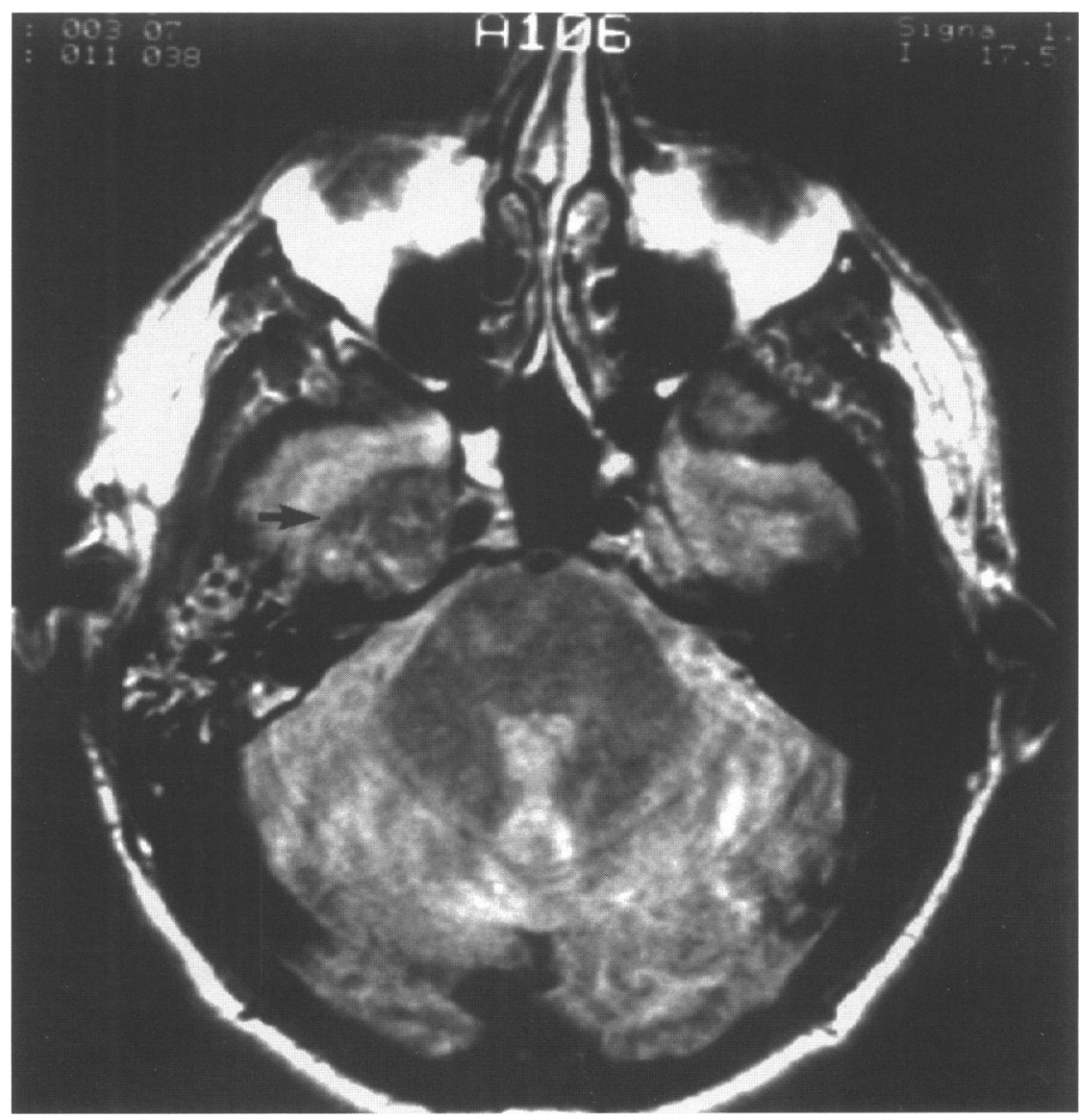



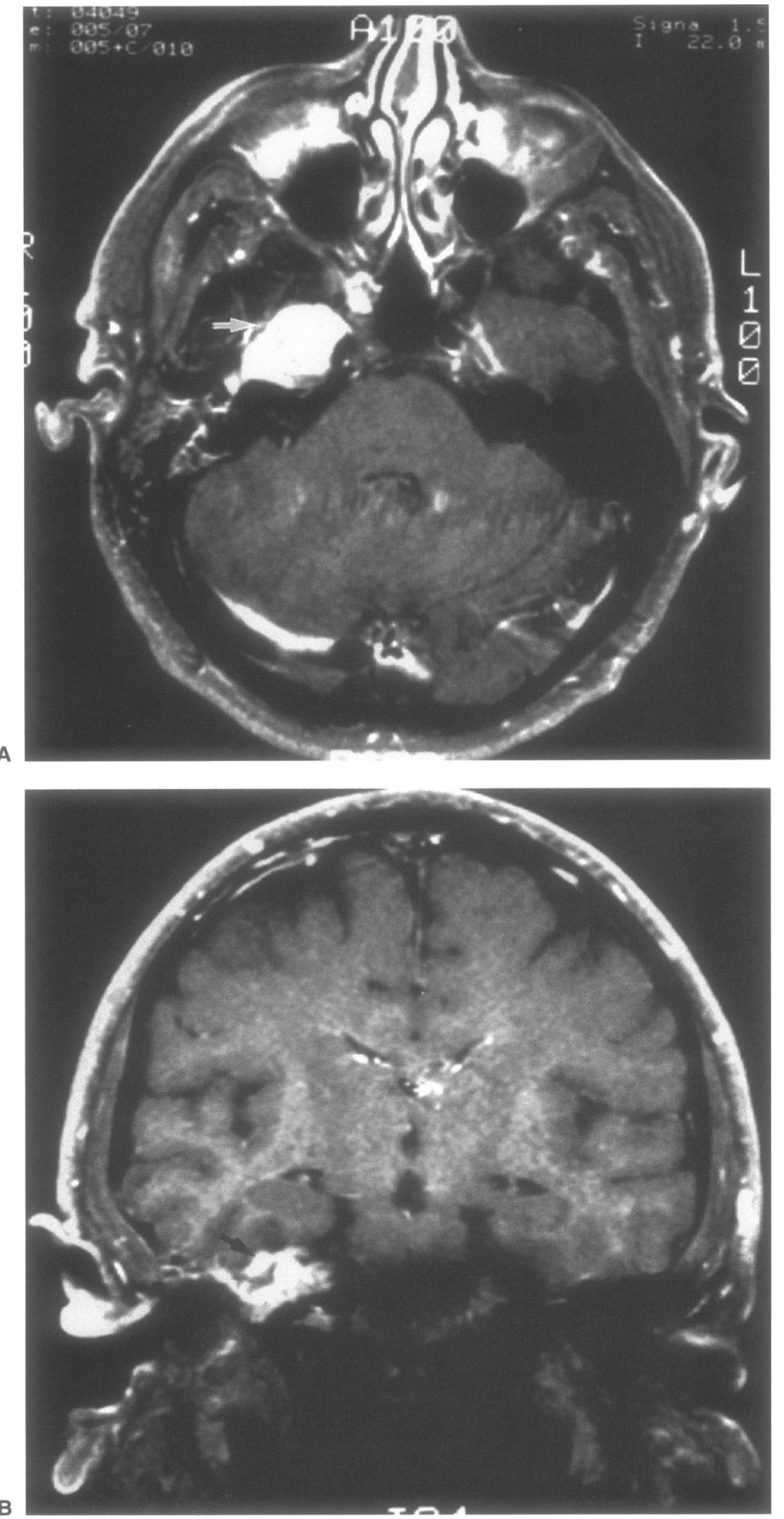

Figure 7. Gadolinium enhanced $\mathrm{T}_{1}$-weighted magnetic resonance imaging scans revealing enhancing tumor involving the right carotid canal and surrounding the petrous carotid artery (arrows). 
fiable nerve. Postoperatively, the patient continues to have normal cranial nerve function and the middle ear effusion resolved after placement of a ventilation tube. Postoperative imaging reveals no residual tumor (Fig. 8).

\section{DISCUSSION}

Primary neoplasms of the petrous apex occur less frequently than lesions of the petrous apex air cell system such as cholesterol granuloma, cholesteatoma, and mucocele. Primary neoplasms of the petrous apex include chordoma, chondrosarcoma, chondroma, and schwannoma. Most schwannomas of the petrous apex are not primary and usually represent extension of tumors from the posterior fossa, jugular foramen, or Meckel's cave. ${ }^{4}$ Primary intraosseous schwannoma is rare and may not appear related to any cranial nerve. ${ }^{5}$ In our patients the tumor appeared to have arisen in the petrous carotid canal. In both patients the tumor encased the carotid artery and greatly enlarged the carotid canal. There are four named nerves that are intimately related to the petrous carotid artery and may have been the neoplastic site of origin. The largest nerve related to the petrous carotid artery and the most frequent cause of schwannoma in the petrous apex is the trigimenal nerve. The inferolateral edge of the trigeminal ganglion is separated from the terminal portion of the horizontal petrous carotid artery by dura only. ${ }^{6}$ The portion of the trigeminal ganglion giving rise to the maxillary and mandibular divisions lies directly above the anterior edge of the horizontal petrous canal. Conceptually, a tumor arising in either the mandibular or maxillary division could extend into the carotid canal and encase the carotid artery. In our second patient, in whom the medial portion of the foramen oval was eroded, the tumor was initially thought to possibly arise from the mandibular division of the fifth nerve. This proved not to be the case at the time of surgery. Also, our patients had normal fifth nerve function both preoperatively and postoperatively, which should rule out the trigeminal nerve as the tumor origin. Both the greater and lesser petrosal nerves lie in the floor of the middle fossa parallel to the horizontal carotid artery. The greater petrosal nerve is directly above the anterior margin of the horizontal segment in $66 \%$, anterior to carotid canal in $20 \%$, and directly above the anterior half of the horizontal canal in $14 \%$ of cases. ${ }^{6}$ Thin bone and, on occasion, only periosteum separate the greater petrosal nerve from the carotid artery. A tumor originating from the greater petrosal nerve could easily invade the carotid canal. However, neither of our patients had a preoperative loss of tearing and both were found to have the greater petrosal nerve running over the dorsal surface of the tumor. The lesser petrosal nerve normally lies anterior to the horizontal carotid canal and is always separated by bone from the horizontal carotid artery. In both of our patients the lesser
Figure 8. Postoperative gadolinium enhanced $T_{1}$-weighted magnetic resonance imaging scans demonstrating complete tumor resection.

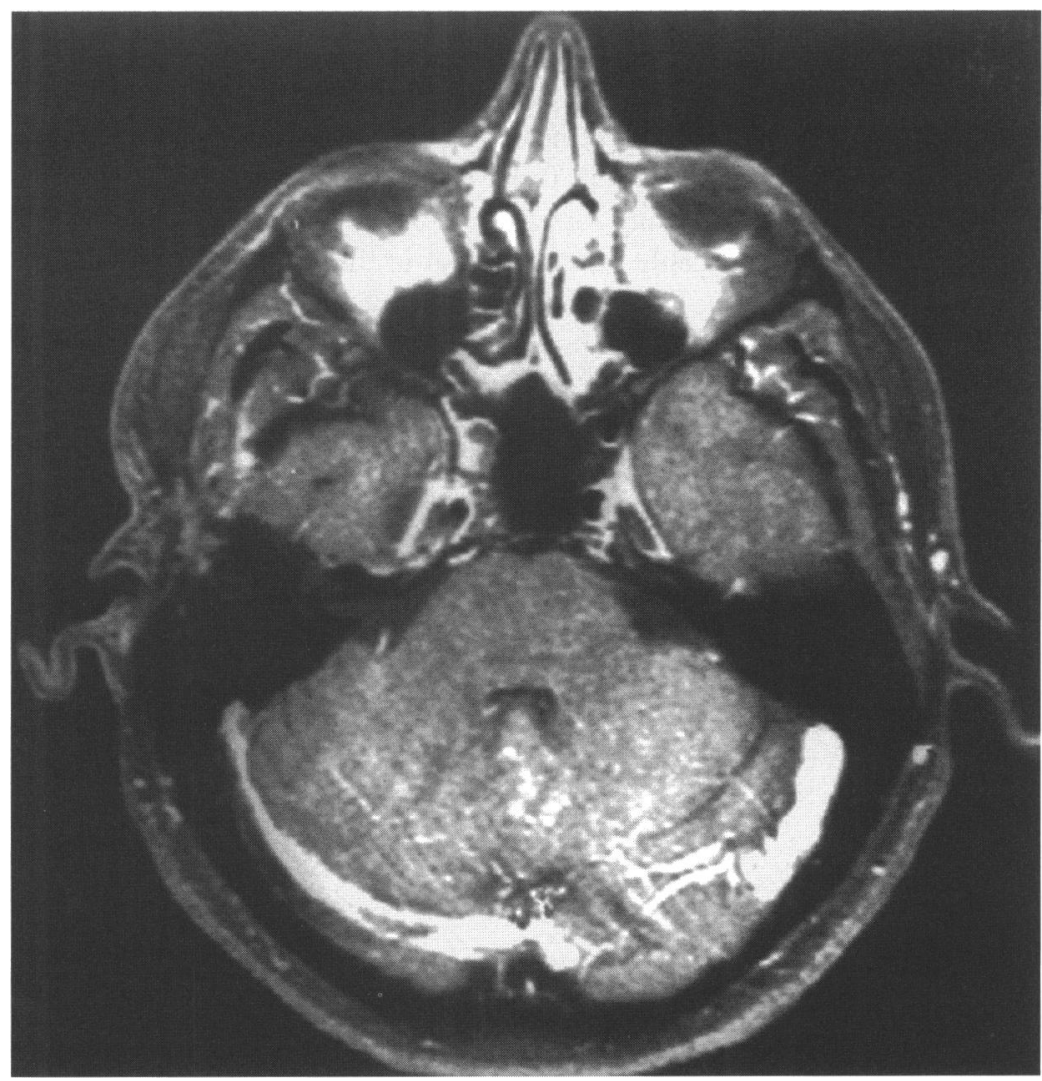


petrosal nerve was anterior to the tumor. Neither the greater nor lesser petrosal nerves were believed to be the origin of the tumor in either of our patients. Finally, the carotid nerve or periarterial sympathetic plexus branches into two parts near the posterior carotid genu. The larger anterior branch is the origin of the deep petrosal nerve, which joins the greater petrosal nerve to form the vidian nerve. ${ }^{6}$ Small branches of this nerve pass through the formina in the vertical carotid canal into the middle ear. We believe that the deep petrosal nerve is the most likely neural origin for the tumor in both of our patients. It would account for tumor encasement of the carotid artery and the generalized erosion of the carotid canal. It would also explain the paucity of preoperative neurologic symptoms despite relatively large tumor size.

Surgical access to primary lesions of the petrous apex was initially developed to treat suppurative petrous apicitis. Streit, ${ }^{7}$ in 1902 , was the first to perform a subtotal petrosectomy for suppuration of the petrous apex. In 1931, Eagleton ${ }^{8}$ published a report describing the unlocking of the petrous apex procedure that combined a retrolabyrinthine approach with a middle fossa transpetrous approach. This approach has been revived for removal of petroclival menigiomas. ${ }^{9}$ Middle fossa access to the petrous carotid was first suggested by Glasscock ${ }^{9}$ in 1969 and the triangle of bone removed from the petrous apex for carotid artery exposure has become known as Glasscock's triangle. ${ }^{10}$ Removal of petroclival tumors via a middle fossa (subtemporal) transpetrous approach was first described by House et al ${ }^{11}$ in 1986. This approach affords wide exposure of the petrous carotid canal except for the lower vertical segment. The anterior portion of the carotid canal is covered by the maxillary and mandibular divisions of the fifth nerve and complete exposure in this area requires transection of these nerves at the rotundum and ovale foramina. The middle fossa transpetrous approach also avoids the hearing loss and facial nerve dysfunction associated with either transcochlear or infratemporal fossa approaches. The middle fossa transpetrous approach was used in our second patient. Except for sacrifice of the greater petrosal nerve, gross tumor removal was accomplished without sacrificing cranial nerve function. Our first patient required a Fisch type B infratemporal fossa approach to remove tumor from the middle ear and from the vertical petrous carotid artery. This approach was used rather than the middle fossa transpetrous approach because of greater involvement of the vertical petrous carotid artery. The exposure necessitated closure of the middle ear with subsequent conductive hearing and once again sacrifice of the greater petrous nerve overlying the tumor.

\section{SUMMARY}

Schwannoma is one of the neoplastic lesions that may occur primarily in the petrous apex. We present two patients with schwannoma arising in the petrous carotid canal. We believe that the most likely neural origin for these tumors was the deep petrosal nerve of the periarterial carotid plexus. Surgical access was accomplished in one patient with a middle fossa transpetrous approach and in the other patient with a Fisch type B infratemporal fossa approach.

\section{REFERENCES}

1. Flood LM, Kemink JL: Surgery in lesions of the petrous apex. Otolaryngol Clin North Am 17:565-575, 1984

2. Franklin DF, Jenkins HA, Horowitz BL, Coker NJ: Management of petrous apex lesions. Arch Otolaryngol 115:1121-1125, 1989

3. Arriaga MA, Brackmann DE: Differential diagnosis of primary petrous apex lesions. Am J Otol 12:470-474, 1991

4. Jackler RK, Parker DA: Radiographic differential diagnosis of petrous apex lesions. Am J Otol 13:561-574, 1992

5. Solodnik P, Som PM, Shugar JM: Intraosseous petrous apex neuroma: CT findings. J Comput Assist Tomogr 10:1027-1029, 1986

6. Paullus WS, Pait TG, Rhoton AL: Microsurgical exposure of the petrous portion of the carotid artery. J Neurosurg 47:713-726, 1977

7. Streit $\mathrm{H}$ : Ein Operationsverfahren suz Eroffnung tiefgelegenen von der Spitze der Felsebeinpyramide ausgehender Epiduralabscesse. Arch Ohrenheilk 57:169-177, 1902

8. Eagleton WP: Unlocking of the petrous apex pyramid for localized bulbar (pontile) meningitis secondary to suppuration of the petrous apex. Arch Otolaryngol 13:386-422, 1931

9. Glasscock ME: Middle fossa approach to the temporal bone. Arch Otolaryngol 90:41-53, 1969

10. Pensak ML, Van Loveren H, Tew JM, et al: Transpetrosal access to meningiomas juxtaposing the temporal bone. Laryngoscope 104:814-820, 1994

11. House WF, Hitselberger WE, Horn KL: The middle fossa transpetrous approach to the anterior-superior cerebellopontine angle. Am J Otol 7:1-4, 1986

12. Horn KL, Hankinson H, Hitselberger WE: The middle fossa transpetrous approach for access to the petroclival region (extended middle fossa approach). In Brackmann DE, Shelton C, Arriaga MA, eds: Otologic Surgery. Philadelphia, WB Saunders, 1994 